\title{
Oral Cavity Sarcoma
}

National Cancer Institute

\section{Source}

National Cancer Institute. Oral Cavity Sarcoma. NCI Thesaurus. Code C5916.

A malignant soft tissue neoplasm that arises from the oral cavity. Representative examples include Kaposi sarcoma and angiosarcoma. 